\title{
Putting out the 'Unwelcome Mat:' The announced Public Charge Rule reduced safety net enrollment among exempt noncitizens
}

\author{
Jeremy Barofsky ${ }^{*}$, Ariadna Vargas, Dinardo Rodriguez, Eva Matos`, \\ Anthony Barrows*
}

\begin{abstract}
Government action shapes the perceived and actual costs of citizens' interactions with the state. By manipulating these costs, policymakers can affect citizens' willingness to engage with the state, strongly impacting short- and long-term wellbeing. In September 2018, the Trump administration announced its intention to change how an immigrant's likelihood of becoming a "public charge" would be evaluated. Once adopted, the rule would penalize certain classes of noncitizens for using safety net programs, potentially jeopardizing their application for permanent residence. We hypothesize that this proposed change increased psychological and learning burdens for low-income immigrants well beyond those directly impacted by the rule. Specifically, we used difference-in-differences models to analyze whether the announcement reduced safety net use among two groups exempt from the rule's provisions: any WIC enrollee and noncitizen SNAP enrollees that are already legal permanent residents, refugees, or asylees. Even though the WIC program was excluded from the proposed rule, we find reductions in overall WIC use after the announcement. In addition, we show that SNAP enrollment decreased differentially after the announcement for noncitizens, nearly all of whom were likely exempt from the rule. Within the conceptual framework of administrative burden, our study provides empirical evidence for government action generating an 'unwelcome mat' effect, whereby citizens unaffected by a public benefits policy are still driven away from safety net use. Given that the public charge rule was adopted in February 2020, weeks before the COVID-19 pandemic began, our findings suggest that the rule continues to threaten public health.
\end{abstract}

Keywords: Public Charge, WIC, SNAP, Immigration, Administrative Burden

\section{Introduction}

$\mathrm{S}$ afety net programs are critical lifelines for families living in poverty, but participation is often low. Takeup estimates vary from less than 15 percent for the State Children's Health Insurance Program (LoSasso \& Buchmueller, 2004), to 50 percent for the Special Supplemental Nutrition Program for Women, Infants, and Children (WIC, Gray et al., 2019), and 70 percent for the Supplemental Nutrition Assistance Program (SNAP, Currie, 2006).

An important determinant of take-up variation in safety net programs is the level of associated administrative burden (Moynihan et al., 2014; Herd \& Moynihan, 2019). Administrative burden can be understood as the cognitive, time, and financial cost demanded of citizens to enroll in and use public programs. Policy designs,

\footnotetext{
*ideas42

Address correspondence to Jeremy Barofsky at (jeremy@ideas42.org)

Copyright: (C) 2021. The authors license this article under the terms of the Creative Commons Attribution 4.0

International License.
} 
broadly conceived, determine how much of this burden citizens must bear compared to how much is taken on by the state. The study of administrative burden's impact on safety net access is relatively rare. However, insights from behavioral economics can shed light on the costs of imposing administrative burdens on people living in poverty. These findings emphasize that seemingly small changes in a choice environment can have outsized impact on decisions and well-being, and that impacts are exacerbated for people experiencing chronic scarcity (Thaler \& Sunstein, 2009; Mullainathan \& Shafir, 2003). This means that families experiencing poverty are likely to face greater difficulties in accessing programs for a given level of burden and implies larger welfare implications from poorly designed policy (Mani et al., 2013).

Administrative burden can be categorized into learning, psychological, and compliance costs (Moynihan et al., 2014). We explore how political action in the US affected the learning and psychological costs of accessing safety net benefits after the "public charge" rule announcement in September 2018. US immigration law permits the denial of permanent residence to individuals deemed likely to become "public charges," or overly reliant on government support. Rumors started immediately after Donald Trump's inauguration in January 2017 that his administration would expand the set of safety net programs that would count toward a public charge determination. However, the formal process to expand the definition didn't begin until September 2018, with an announcement of the administration's intention to include noncash programs such as Medicaid and SNAP. While the eventual proposed rule excluded WIC, administration actions likely added to confusion about whether use of that program could jeopardize one's immigration status as well (NWA, 2017; NWA, 2018).

While the final rule change was formally adopted in February 2020, we study the effect on safety net enrollment after the administration's first step: the proposed rule's announcement. By doing so, we examine behavior change caused by psychological and learning costs, before there were any direct changes to compliance costs. We analyze whether the public charge announcement generates 'chilling effects' on safety net enrollment among two groups exempt from the announced rule: SNAP enrollees that are already legal permanent residents, refugees, or asylees and WIC participants. Using data from California and Washington State, we hypothesized that if the public charge rule created chilling effects for noncitizens, we would observe larger declines in WIC participation in counties with high- compared to low- noncitizens shares, and after the announcement compared to before. Our findings confirm this hypothesis, showing a differential decline in counties with highnoncitizen shares for total WIC enrollment and separately for children under five and women's enrollment, as well.

We also investigate SNAP enrollment using data from the Minnesota Department of Human Services (MNDHS). These data include separate SNAP enrollment counts for citizens and noncitizens and allow us to estimate what percent of noncitizens are likely exempt from the public charge rule. Consistent with other research, we find that $95 \%$ of noncitizen SNAP enrollees in Minnesota fall into categories likely exempt from the rule (Capps et al., 2020). Given this, we focus on changes in SNAP enrollment for citizens compared to all noncitizens and pre- versus post-public charge rule announcement. We hypothesized that SNAP enrollment would fall more for noncitizens than citizens immediately after the public charge rule announcement. We illustrate that, compared to citizens, noncitizen SNAP enrollment does indeed decline sharply coincident with the rule's announcement.

Our results show that political actions which affect residents' ability and willingness to interact with the state are often felt well beyond those directly affected by a rule or law. That is, we document an empirical instance of the government putting out an "unwelcome mat" to noncitizens that effectively discourages safety net use well beyond the targeted group. Although the concept of an unwelcome mat is mentioned in passing elsewhere (Alker \& Pham, 2018), we develop it more fully here and within the theoretical framework of administrative burden. In particular, we analyze the public charge rule as an instance of the Trump administration's broader effort to gain politically by using the administrative state to restrict access to government services for racialized minority groups. Given the racial composition of noncitizens in the U.S., targeting immigrants by definition differentially harms nonwhite populations. We find that the Trump administration's 'unwelcome mat' extended beyond individuals subject to the rule change and reduced safety net use among exempt groups. Given its rhetoric and stated goals, we conclude that this outcome was the intentional consequence of the administration's racialized policy of exclusion. Since safety net programs decrease poverty and improve short- and longterm health, reduced immigrant access would be harmful at any time. However, the damage has been signifi- 
cantly worsened by the COVID-19 pandemic, especially since immigrants constitute a large proportion of essential workers and have experienced disproportionate mortality and job loss as a result (Clark et al. 2020; Gelatt, 2020).

\section{Policy context}

The Immigration Act of 1882 first limited migration to the continental United States on the basis of selfsufficiency by excluding entry to individuals believed to be "idiots, lunatics, convicts, and persons likely to become a public charge" (USCIS, 2019). Since 1999, legal immigrants could be deemed a public charge only for using cash benefits programs such as Temporary Assistance for Needy Families (TANF). In September 2018, the Department of Homeland Security (DHS) officially introduced the proposed changes to the public charge rule, expanding the list of public benefits programs that, if used, would classify noncitizens as a public charge. The proposed expansion included programs like Medicaid, SNAP, and federal housing assistance, but exempted WIC. The announcement also excluded noncitizen refugees or asylees and legal permanent residents renewing their green cards or applying for citizenship.

While the proposed rule excluded WIC, a draft Executive Order leaked after President Trump's inauguration in January 2017 asked DHS to revisit the definition of a public charge. It did not specify which noncash safety net programs would be considered and this ambiguity led some to assume WIC was included in the rule (NWA 2017; Fix \& Capps, 2017). Additionally, on February 2018, a leaked draft Notice of Proposed Rulemaking (NPRM) by DHS explicitly included WIC usage as a factor that could impact permanent residency (NWA, 2018). Although an NPRM carries no legal weight, this step further increased ambiguity about WIC's inclusion.

Other evidence suggests that policy ambiguity affects safety net usage. For example, having a noncitizen family member in the household was found to keep eligible children of noncitizens from enrolling in Medicaid relative to children of citizens (Acevedo-Garcia \& Stone, 2008). In addition, mixed-status households avoided WIC at higher rates as deportation risk in their community increased (Vargas \& Pirog, 2016). Similarly, aggressive immigration enforcement reduced Medicaid enrollment for citizen children after welfare reform (Watson, 2014) and Medicaid coverage dropped for mixed-status households compared to non-mixed-status households in states that did not expand Medicaid under the Affordable Care Act (ACA), and that had more aggressive immigration law enforcement (Cohen \& Schpero, 2018). The psychological costs (and anticipated consequences) of the public charge rule are undoubtedly amplified by fears of enhanced immigration enforcement, meaning that the expansion in deportation during the Trump administration likely worsened the stress caused by the public charge rule announcement.

In contrast, there is evidence that widespread outreach and reduced hassles can increase access to safety net programs, generating a 'welcome mat' effect for the eligible, but unenrolled. For instance, Medicaid coverage increased significantly for previously eligible children in families with low incomes in both Massachusetts after insurance expansion (Sonier et al., 2013) and nationwide after the ACA's implementation (Hudson \& Moriya, 2017). In addition, Medicaid expansions that made more working-age adults eligible increased program enrollment among low-income older adults previously eligible for both Medicare and Medicaid (McInerney, Mellor \& Sabik, 2021).

\section{Political context}

To explain how the public charge announcement could reduce safety net enrollment well beyond the narrow group of noncitizens it threatened, the rule must be understood as one episode in America's long-standing battle for political power using race. First, we note that when immigrants enter the U.S., they take their position within a socially stratified nation that always has and continues to racialize its population (Sáenz and Douglas, 2015). By racialization, we mean the process of extending racial meaning to a previously unclassified group, which both defines that group's position within the preexisting race-based social order as well as determines its access to citizenship rights, economic opportunity, and public services. Race can be understood as a historically flexible social construction that is "constantly being transformed by political struggle," (Omi \& Winant, 2014). In the U.S, those holding political power have defined the white in-group to contrast against the non-white other and associated the latter with negative characteristics such as laziness, criminality, or being oversexed 
(Bonilla-Silva, 2001). Since group membership helps determine access to government resources, racialization generates real differences in life chances that reinforce these associations.

Well before the presidency of Donald Trump, the Republican Party embraced an electoral strategy of white identity politics, using "electoral appeals that were increasingly strident, alarmist, and racially charged" (Hacker \& Pierson, 2020). Using the associations described above, these appeals were predicated on racial stratification based in white supremacy (Bonilla- Silva, 2001). The Trump campaign and administration supercharged this political strategy. Trump announced his presidential run by accusing Mexican immigrants of bringing crime and drugs to the U.S. (Gamboa, 2015) and pursued a policy of punishment against racialized minorities. ${ }^{1}$ Since US-born residents are $76 \%$ white, while the foreign-born are $46 \%$ white (including those identifying as Hispanic/Latinx; MPI 2020), targeting noncitizens by definition differentially hurts nonwhite families. The sentiments fomented for political gain through the public charge rule are well-summarized in a description of the Tea Party movement's origins: "Opposition is concentrated on resentment of perceived federal government 'handouts' to 'undeserving' groups, the definition of which seems heavily influenced by racial and ethnic stereotypes," (Williamson et al. 2011; Vickery 1974). See Supplementary Appendix section 1 for additional detail on the public charge rule and its political background.

\section{Theoretical background}

\section{Administrative Burden}

Administrative burden can be understood as the costs people experience in learning about services (learning costs), complying with the rules, requirements, and paperwork needed to obtain public benefits (compliance costs), and feeling the stress, loss of autonomy, and stigma throughout the process of accessing safety net programs (psychological costs; Moynihan et al., 2014). By focusing on the effect of the Trump administration's public charge rule before adoption, this analysis identifies the impact of changes to psychological and learning costs, while direct compliance costs remain constant.

Learning costs can have a large effect on take-up, as people experience barriers while collecting information, understanding eligibility, and navigating applications. This barrier can significantly impede benefits access and is worsened by language barriers as well as elevated stress or fear. For example, about half of eligible nonparticipants for SNAP believe they are not eligible, while reporting that they would apply if they knew for certain they could (Bartlett et al. 2004). Similarly, psychological costs such as stress and fear may lead individuals to avoid accessing safety net programs at all. In one illustration of learning costs' effects and their interaction with psychological effects, researchers exploit the fact that some states require TANF recipients to fulfill work requirements to access Medicaid, creating a perception that Medicaid work requirements are also required for non-TANF recipients. They find 10\% lower Medicaid uptake for non-TANF individuals in states with the Medicaid work requirement for TANF recipients compared to states without this requirement (Venkatarami et. al., 2020).

\section{Learning and Psychological Costs of the Announced Public Charge Rule}

The announced change in the public charge rule increased learning and psychological burdens among noncitizens accessing the safety net. According to the Urban Institute's December 2018 Well-Being and Basic Needs Survey (WBNS) of immigrant families, the majority of immigrant adults $(62.9 \%)$ reported awareness of the public charge rule. The survey found that one in seven immigrant adults $(13.7 \%)$ and over one fifth (20.7\%) of adults in low-income families reported 'chilling effects,' meaning the respondent or a family member reported not using a government noncash program because of fears over green card status. Among those that reported chilling effects, 44\% reported avoiding SNAP enrollment specifically. Avoidance was also higher for Hispanic adults in immigrant families compared to non-Hispanic individuals. Respondents reported the highest levels of trust in information from government agencies but said that the most common source of public charge information was the news, social media, or social networks (Bernstein et al., 2019). Since the administration's proposed policy change did not include any accompanying effort to explain who was affected and because trustworthy information was in short supply, the learning cost burden fell exclusively on the immigrants potentially impacted. 
The December 2019 round of the WBNS revealed slightly larger chilling effects one year later, while asking a broader range of questions that revealed continued uncertainty about what groups and programs would be affected by the rule. Fifteen months after the first formal announcement, $66 \%$ of respondents were confident in their understanding of the rule, but only $23 \% \mathrm{knew}$ that it would not apply to citizenship applications. Interested to measure broader chilling effects, the 2019 round also asked whether respondents avoided WIC even though it was not named in the rule. Among adults who reported avoiding government benefit programs because of immigration concerns, 16\% avoided WIC and 48\% avoided SNAP (Bernstein et al., 2020). The announced rule change therefore imposed learning costs on individuals with limited access to accurate information, while raising the psychological costs of those exempt from the rule by increasing fears that safety net use would jeopardize their own residency status or that of their household members.

\section{The Trump Administration's Public Charge Rule as Administrative Burden}

To elucidate how the public charge rule announcement made use of racialized stereotypes to deny citizenship rights through administrative burden, we apply Kahn, Katz, \& Gutek (1976)'s theory of 'organizational transactions.' ${ }^{2}$ Under this framework, the public charge rule announcement was initiated by government and increased fear and uncertainty about the consequences of safety-net use among eligible individuals outside government. This action represented state "outreach" - the unwelcome mat - with the threat of revoking alreadygranted residency rights exerting a disproportionate effect on racialized minorities. The administration's threatening message was magnified by substantially expanding the scope and reach of immigration enforcement (Shear \& Nixon, 2017), which heightened already-elevated deportation fears (Asad, 2020).

In addition, the public charge announcement was amplified through media coverage, social networks, and by affecting the actions of lower-level government bureaucrats and immigrant advocates. For the former, we showed in other work that the announced change led to a steep rise in media mentions of the public charge rule (Bernstein et al., 2019). ${ }^{3}$ The announced rule also affected how social service officials shared eligibility and enrollment information with potential applicants by signaling and shaping these workers' perceptions of what type of person should use benefits (NWA, 2017; NWA, 2018). Even if these officials did not share the policy's aims, they may have discouraged enrollment or limited encouragement for racialized minorities based on fear or confusion about the policy' applicability.

In summary, the administration unleashed its racialized unwelcome mat using the state, with the intention of changing the behavior of nonstate safety-net users. The unwelcome mat message was amplified by interactions between potential safety-net users and other nonstate actors such as the media, friends and family, and the advocacy community. Introduced by the state, the message that safety-net use could lead to deportation cumulatively reduced the probability that immigrants and their families would begin bureaucratic encounters to access government programs. Most studies of administrative burden focus on this final step: the bureaucratic response to individuals seeking public benefits (Heinrich, 2016). Less attention has been paid, however, to why individuals decide to initiate those interactions in the first place and how those decisions are mediated by group memberships. By examining a form of administrative burden that operates through transactions initiated within the bureaucracy and is amplified by entities outside it, we seek to extend the relatively small literature that documents state-initiated burden where non-state actors are engaged to magnify effects.

\section{Methods}

\section{Data}

WIC Enrollment Data from California and Washington State

Monthly WIC enrollment data by county was available for the states of California and Washington from January 2015 to June 2019. California WIC enrollment data from January 2015 to December 2018 came from publicly reported state agency data, and enrollment from January 2019 to June 2019 was provided by request from California's Department of Public Health. Washington's WIC enrollment data was provided by request from Washington's Department of Health.

SNAP Enrollment Data from Minnesota 
We also used administrative data provided by the MNDHS, which included two data sets. The first provided monthly SNAP enrollment counts across Minnesota's 87 counties from January 2015 to June 2019 separately by citizenship status. The second consisted of monthly enrollment counts for citizens, noncitizens likely exempt from the public charge rule, noncitizens likely subject to the public charge rule. Noncitizens were categorized as likely exempt from the public charge rule if they were either legal permanent residents, asylees, or refugees. To be conservative, noncitizens not in one of those categories were included as likely subject to the public charge rule. To comply with anonymity requirements, counties were aggregated into six larger regions in this second data set. The Supplementary Appendix Section 2 provides additional detail on data acquisition and definitions, while Supplementary Appendix Section 6 provides detail on each state's immigrant profile and how each were affected by the pandemic.

\section{Outcomes and Controls}

For WIC data, the outcome analyzed was monthly WIC enrollment per capita. Since WIC participants were either pregnant women and mothers, or children under five, we also investigated effects for the following outcome variables: enrollment of WIC mothers per capita and a county's share of children under five enrolled in WIC. County population and under-five population per county per year was obtained from U.S Census Bureau.

For Minnesota SNAP data, the outcome analyzed was relative monthly enrollment for citizens compared to noncitizens by county and relative monthly enrollment separated into citizens and noncitizens exempt from the public charge rule for the six aggregated regions. Relative enrollment was calculated by dividing monthly enrollment by the average monthly enrollment at the beginning of our data period used for analysis (January to March 2016). Each group's monthly enrollment levels were therefore normalized to approximately one hundred for comparability given that SNAP enrollment is an order of magnitude larger for citizens compared to noncitizens.

\section{Empirical Analysis}

To estimate the causal effect of the public charge announcement on WIC, we compared changes in enrollment before and after September 2018 in counties with different noncitizen population shares. We estimated effects in difference-in-differences (DID) models, adjusting for state and year fixed effects to control for time-invariant state and year characteristics, and month fixed effects, to control for seasonality in enrollment. The monthly unemployment rate was used to control for economic conditions and was allowed to vary by state to account for differences in the relationship geographically. To control for annual state-specific policy variation, state-byyear controls are also used. Regressions were weighted by county population and standard errors were clustered at the county level using data from January 2016 to June 2019. For robustness, we investigated effects both without population weights and using data from January 2015 to June 2019. To interpret the results of a DID model as causal, we first verify that the outcome in the comparison group mirrors the policy-affected group before the policy change occurs. We therefore plot WIC enrollment separated into quartiles by their noncitizen population share and over time to assess parallel trends.

For SNAP, we estimated the difference in relative enrollment before and after the public charge rule announcement and for citizens compared to noncitizens. We also validate the assumption that relative SNAP enrollment exhibits similar trends pre-announcement for these two groups. Controls are included for year, month, and monthly unemployment rate to adjust for time-invariant shocks, seasonality, and differences in economic conditions, respectively. Regressions are weighted by county population, but we also exclude population weights to check sensitivity, while standard errors are clustered at the county level. To extend this analysis, we use the same DID model to also investigate changes in relative enrollment between citizens compared to noncitizens likely exempt from the public charge rule, after the rule's announcement across the six aggregated geographic regions of Minnesota.

Using data from Spanish- and English-language news media in the U.S., Gonzalez et al. (2020) show that there is a sharp increase in exposure to public charge related information coincident with the proposed rule's announcement. This justifies the post announcement definition used as beginning in October 2018. The Supplementary Appendix Section 3 provides additional detail on our empirical approach and Section 5 describes 
state and federal policies beyond the public charge rule that could have impacted immigrants and safety net participation in the same timeframe.

Table 1

Summary Statistics for WIC and SNAP Data

Panel A California and Washington State WIC enrollment

\begin{tabular}{|c|c|c|c|c|c|c|c|c|}
\hline & \multicolumn{4}{|c|}{ Pre-announcement } & \multicolumn{4}{|c|}{ Post-announcement } \\
\hline & Mean & $\begin{array}{l}\text { Std. } \\
\text { Dev }\end{array}$ & $\begin{array}{l}25^{\text {th }} \\
\text { Per. }\end{array}$ & $\begin{array}{l}75^{\text {th }} \\
\text { Per. }\end{array}$ & Mean & $\begin{array}{l}\text { Std. } \\
\text { Dev }\end{array}$ & $\begin{array}{l}25^{\text {th }} \\
\text { Per. }\end{array}$ & $\begin{array}{l}75^{\text {th }} \\
\text { Perc. }\end{array}$ \\
\hline Population & 497,477 & $1,202,326$ & 41,838 & 445,519 & 490,537 & $1,193,264$ & 35,556 & 446,569 \\
\hline$\%$ Noncitizen & 12.47 & 4.35 & 10.75 & 17.19 & 12.45 & 4.36 & 10.75 & 17.19 \\
\hline$\%$ Unemployment & 4.92 & 1.75 & 4.14 & 5.18 & 4.27 & 1.56 & 3.71 & 4.21 \\
\hline$\%$ WIC Child & 7.39 & 2.54 & 5.27 & 9.38 & 6.36 & 2.33 & 4.50 & 7.97 \\
\hline$\%$ WIC Women & 0.56 & 0.23 & 0.38 & 0.65 & 0.47 & 0.21 & 0.31 & 0.53 \\
\hline$\%$ WIC Total & 2.49 & 1.09 & 1.60 & 2.96 & 2.11 & 0.99 & 1.34 & 2.46 \\
\hline
\end{tabular}

Panel B. Minnesota SNAP Enrollment

\begin{tabular}{|c|c|c|c|c|}
\hline & \multicolumn{2}{|c|}{ Pre-announcement } & \multicolumn{2}{|c|}{ Post-announcement } \\
\hline & Total & $\begin{array}{c}\text { Total } \\
\text { (\% state } \\
\text { population) }\end{array}$ & Total & $\begin{array}{l}\text { Total } \\
\text { (\% statepop- } \\
\text { ulation) }\end{array}$ \\
\hline Population & $5,375,552$ & 100 & $5,563,646$ & 100 \\
\hline Total SNAP Enrollment & 467,062 & 8.69 & 416,864 & 7.49 \\
\hline Citizens & 429,639 & 7.99 & 384,690 & 6.91 \\
\hline Noncitizens & 37,338 & 0.69 & 32,174 & 0.58 \\
\hline $\begin{array}{l}\text { Noncitizens Likely Exempt from } \\
\text { the Public Charge Rule }\end{array}$ & 35,479 & 0.66 & 30,505 & 0.55 \\
\hline County Data: SNAP Relative Enrollmen & & & & \\
\hline Citizens & 96.92 & - & 91.09 & - \\
\hline Noncitizens & 96.49 & - & 84.10 & - \\
\hline Region Data: SNAP Relative Enrollment & & & & \\
\hline $\begin{array}{l}\text { Citizens } \\
\text { Noncitizens Likely Exempt from } \\
\text { the Public Charge Rule }\end{array}$ & 95.60 & - & 87.76 & - \\
\hline
\end{tabular}

Source: Population statistics are from the US Census Bureau; noncitizen data come from the 2016 American Community Survey, 1-Year Estimates; unemployment rates are from the Bureau of Labor Statistics; data on monthly enrollment in SNAP were shared by Minnesota's Department of Human Services, and total and per capita enrollment statistics are author's calculations. Region data refers to an aggregation of Minnesota's 87 counties into six regions to comply with small-cell anonymity requirements. Noncitizens exempt from the public charge rule are defined as noncitizens that are either refugees, asylees, or are permanent U.S. residents.

\section{Results}

\section{Summary Statistics}

Table 1, panel A summarizes county-level WIC enrollment data from California and Washington pre- and postannouncement. In these two states, we observe the mean noncitizen share is $12.5 \%$, WIC enrollment per capita 
declines from $2.5 \%$ to $2.11 \%$ in pre- compared to post-announcement months, while $7.4 \%$ and $6.4 \%$ of children are enrolled in WIC in the pre- and post-announcement periods.

Table 1, panel B shows county- and region-level Minnesota SNAP enrollment data from January 2016 to June 2019. We observe that $8.69 \%$ of Minnesota's population received SNAP each month pre-announcement and this declined to $7.49 \%$ post-announcement. Total SNAP enrollment among citizens was more than ten times greater than for noncitizens pre- and post- announcement. The main outcome of interest, relative SNAP enrollment, using county data decreased from 96.9 to 91.1 and 96.5 to 84.1 from pre- to post-announcement for citizens and noncitizens, respectively. Importantly, the table also shows that $95 \%$ of noncitizens can be classified as likely exempt from the public charge rule both pre- and post-announcement. Given the small proportion of SNAP noncitizens potentially subject to the rule, we proceed by focusing our analysis on relative SNAP enrollment among noncitizens overall and interpret results as reflecting the behavior of noncitizens likely exempt from the public charge rule.

\section{Effect of the Public Charge Announcement on WIC enrollment}

First, we confirm that WIC enrollment per capita trends before the public charge rule announcement are similar across low- and high-noncitizen share counties. Figure S.1 plots per capita WIC enrollment where counties in California and Washington are split into four equal-population groups by their noncitizen share. It shows that, before the public charge rule announcement, per capita WIC enrollment across county groups exhibit remarkably similar trends. Irrespective of noncitizen share, we also observe consistent declines in WIC enrollment across counties, with higher per capita WIC enrollment in counties with greater noncitizens shares. This confirms the DID assumption of parallel trends and permits a causal interpretation of the results. Post-announcement, we find a small, but discernible decline in WIC enrollment, especially for counties in the highest two noncitizen-share groups.

Table 2

Effect of the Public Charge Rule Announcement on WIC Monthly Enrollment in California and Washington State (January 2016 - June 2019)

\begin{tabular}{lccc}
\hline \hline & $\begin{array}{c}\text { Children } \\
\text { b/se }\end{array}$ & $\begin{array}{c}\text { Women } \\
\text { b/se }\end{array}$ & $\begin{array}{c}\text { Total } \\
\text { b/se }\end{array}$ \\
\hline Post Announcement & 0.504 & 0.036 & 0.193 \\
& $(0.397)$ & $(0.032)$ & $(0.150)$ \\
County Noncitizen Share (\%) & $0.207^{* *}$ & $0.013^{* *}$ & $0.072^{* *}$ \\
& $(0.102)$ & $(0.006)$ & $(0.028)$ \\
Post Announcement * Noncitizens Share (\%) & $-0.056^{* *}$ & $-0.004^{*}$ & $-0.023^{* *}$ \\
& $(0.026)$ & $(0.002)$ & $(0.010)$ \\
Unemployment rate & $0.798^{* * *}$ & $0.086^{* * *}$ & $0.400^{* * *}$ \\
& $(0.284)$ & $(0.026)$ & $(0.126)$ \\
Constant & 0.972 & -0.021 & -0.416 \\
& $(1.757)$ & $(0.165)$ & $(0.775)$ \\
R-squared & 0.507 & 0.575 & 0.578 \\
$\mathrm{~N}$ & 3,960 & 3,960 & 3,960 \\
\hline
\end{tabular}

$* \mathrm{p}<0.10,{ }^{* *} \mathrm{p}<0.05, * * * \mathrm{p}<0.010$

Source: Author's calculations

Notes: OLS regressions include state, month, year, and state by year fixed effects; county level data are included for both states; calculations weighted by 2016 county population. 
Table 2 shows the effect of the public charge announcement on WIC enrollment overall and separately for women, and for children under five. We observe that a one-point increase in a county's noncitizen share is associated with a further 0.023 (95\% CI: -0.042 , - 0.003 , p-value: 0.026$)$ percentage point decline in WIC enrollment for California and Washington State after the announced public charge rule. This change represents a $0.8 \%$ decline from the mean WIC enrollment share of $2.79 \%$. The effect implies that the WIC enrollment share declined by 0.52 percentage points more in counties in the 75 th percentile of noncitizen share compared to counties in the 25th percentile after the public charge announcement. If applied nationwide, this means the public charge rule announcement was associated with a WIC enrollment decrease of over 28,000. Table S.1 in the Supplementary Appendix shows these results are robust to the inclusion of 2015 enrollment data, table S.2 demonstrates similar results when county population weights are dropped, and table S.3 confirms these findings when excluding state by year fixed effects. Section 4 in the Supplementary Appendix describes these analyses in detail.

\section{Effect on SNAP Enrollment}

Figure 1 displays relative SNAP enrollment in Minnesota for citizens compared to noncitizens January 2016 to June 2019. First, we confirm that these groups experience similar declines in relative enrollment pre-announcement, which validates the parallel trends assumption. Next, we observe that for citizens, SNAP enrollment declines to $91 \%$ of its Q1 2016 level by mid- 2019, but for noncitizens decreases to about 84\%. The figure also shows almost an immediate divergence in previous trends coincident with the public charge rule's announcement for noncitizens compared to citizens. Table 3 confirms these patterns with DID models. Column 1 uses county-level data to calculate that relative SNAP enrollment among noncitizens declines by 6.3 percentage points (95\% CI: -10.3, -2.3; p-value: 0.003) more than for citizens post-announcement. Column 2 uses the sixregion aggregated data to investigate relative SNAP enrollment in noncitizens likely exempt from the public charge rule compared to citizens. Similar to the county data, we find that this model implies a 5.9 percentage point (95\% CI: - 9.9, -1.8; p-value: 0.014) decline in relative SNAP enrollment for noncitizens likely exempt from the rule compared to citizens. Table S.4 in the Supplementary Appendix shows robustness to dropping county population weights, and figure S.2 and table S.5 displays the differential decline in SNAP per capita enrollment for noncitizens compared to citizens, instead of relative enrollment. Section 4 in the Supplementary Appendix describes these analyses in detail.

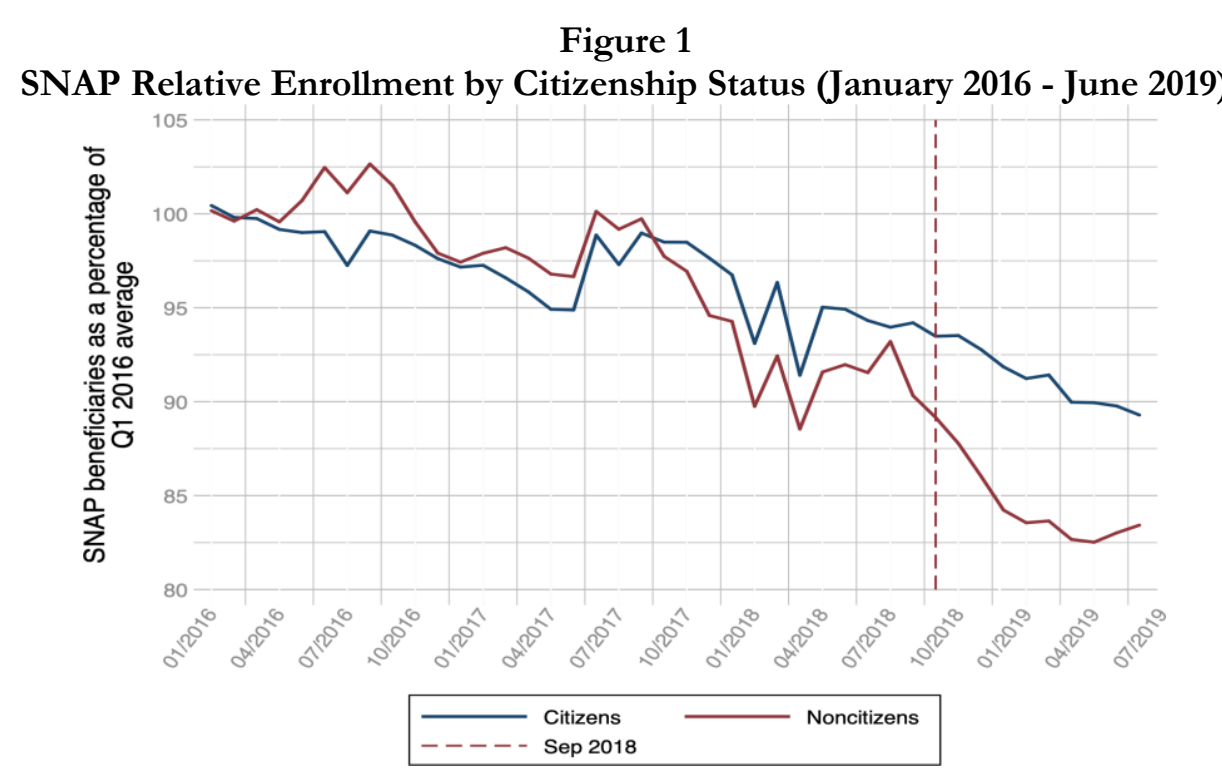

Source: Author's calculations from Minnesota data.

Note: SNAP monthly enrollment is relative to average monthly SNAP enrollment by citizenship status January- March 2016 where a value of 100 equals SNAP enrollment in thatperiod. 
Table 3

Effect of the Public Charge Rule Announcement on SNAP Relative Enrollment in Minnesota (January 2016 - June 2019)

\begin{tabular}{|c|c|c|}
\hline & $\begin{array}{l}(1) \\
\mathrm{b} / \mathrm{se}\end{array}$ & $\begin{array}{l}(2) \\
\mathrm{b} / \mathrm{se}\end{array}$ \\
\hline Post Announcement & $\begin{array}{c}2.234 * * \\
(0.021)\end{array}$ & $\begin{array}{c}1.058 \\
(0.798)\end{array}$ \\
\hline Noncitizen Enrollment & $\begin{array}{l}-1.831 \\
(0.364)\end{array}$ & - \\
\hline Post Announcement * Noncitizen Enrollment & $\begin{array}{c}-6.282^{* * *} \\
(0.003)\end{array}$ & - \\
\hline Enrollment for Noncitizens Exempt from the Public Charge Rule & - & $\begin{array}{r}1.411 \\
(1.560)\end{array}$ \\
\hline $\begin{array}{l}\text { Post Announcement * Enrollment for Noncitizens Exempt } \\
\text { fromthe Public Charge Rule }\end{array}$ & - & $\begin{array}{c}-5.876^{* *} \\
(1.576)\end{array}$ \\
\hline Unemployment rate & $\begin{array}{c}0.582 \\
(0.906)\end{array}$ & $\begin{array}{c}3.385^{* * *} \\
(0.453)\end{array}$ \\
\hline Constant & $\begin{array}{c}96.873^{* * *} \\
(0.005)\end{array}$ & $\begin{array}{c}83.689 * * * \\
(1.981)\end{array}$ \\
\hline R-squared & 0.422 & 0.838 \\
\hline $\mathrm{N}$ & 2,726 & 492 \\
\hline
\end{tabular}

${ }^{*} \mathrm{p}<0.10,{ }^{* *} \mathrm{p}<0.05,{ }^{* * *} \mathrm{p}<0.010$

Source: Author's calculations

Notes: OLS regressions include state, month, year, and state by year fixed effects; county level data are included for both states; calculations weighted by 2016 county population.

\section{Discussion and Conclusion}

We show that the public charge announcement reduced safety net program uptake among individuals exempt from the rule. Unlike most safety net programs, WIC allows enrollment for all noncitizens, including undocumented residents and legal noncitizens without permanent residency. Even though the rule change excluded WIC, potential immigrant enrollees likely perceived that participation increased deportation risks given the administration's ambiguity, lack of effort in explaining the new rule, and broader assault in rhetoric and action on immigrant communities. Using unique data on SNAP enrollment by citizenship status, we first confirm that the vast majority of SNAP enrollees in Minnesota are likely exempt from the rule and then show that SNAP participation for noncitizens decreased differentially post public charge announcement compared to citizens. Although there are substantial differences in the racial breakdown of immigrants across the states analyzed, we find consistency in that the Trump administration's intentional effort to broadly target immigrants drove them away from the safety-net in all three states.

Overall, we show that the public charge announcement generated a racialized and anti- immigrant 'unwelcome mat' that extended well-beyond those narrowly affected by the rule's provisions. Our findings also provide an example of how policy can shape the way in which government is experienced differently across racial groups (Ray, 2019). The Trump administration used the public charge rule to institutionalize racial inequality by diminishing the agency of nonwhite individuals, intentionally using misinformation and ambiguity to restrict immigrant families' choice. In contrast to direct appeals for racial exclusion, it was able to achieve a racialized rationing of benefits in a more insidious way: by threatening immigrants into retreating from the safety-net system. 
In applied behavioral science parlance, these results show that the administrative burden imposed by the public charge rule announcement was a "sludge:" the imposition of excessive frictions such that choice architecture was shifted and achieving one's goals became more difficult (Thaler, 2018). Sludges are welfare-reducing by definition, whereas some administrative burdens can be socially useful. Most sludges increase the complexity or administrative costs associated with signing up for programs (Sunstein, 2019). Although all sludges are rightly described as hidden and difficult to track, they often produce observable evidence: long lines, extended waits, and forms whose onerousness is compounded by the difficulty of finding them in the first place. Similar concepts such as the 'welcome mat' or the 'woodwork' effect (Sommers \& Epstein, 2011) raise safety net participation by affecting all three administrative burden costs. In contrast, the 'unwelcome mat' effect analyzed here influences psychological and learning costs alone, making it more difficult still to observe and, therefore, more pernicious. Understood as an effort to target immigrants and use government institutions to benefit politically from anti-immigrant sentiment, it is not surprising that the racialized 'unwelcome mat' we describe caused broader reductions in safety net use. This was, in fact, its intention. Although government could impose an 'unwelcome mat' using myriad out-group definitions (eg: religion or ethnicity), throughout U.S. history, race has been the most common mediator of access to opportunity using public policy (Katznelson, 2005; Rothstein, 2017).

COVID-19 intensified the damage caused by the public charge rule. Immigrants are disproportionately employed in low-wage service jobs that are incompatible with remote work and therefore incur higher risk of disease transmission. One in five immigrants are essential workers in health care, food services, agriculture, construction, and public transportation (Budiman, 2020). Consequently, Black, Asian, and Hispanic Americans were, respectively, 37\%, 53\%, and 16\% more likely to die than white Americans after a COVID-19 infection (Keating et al., 2020). These mortality differentials mean that life expectancy is projected to decline by 2 and 3 years for Black and Latino populations compared to a decline of 0.68 for white Americans (Andrasfay \& Goldman, 2021). Jobs with a particularly high concentration of immigrants exhibited even larger disparities. In California, Latino food or agricultural workers experienced a 59\% increase in mortality compared to previous years, while white food or agricultural workers experienced a $16 \%$ increase (Chen et al., 2021). Meatpackers - a job overwhelmingly filled by immigrants - also experienced high infection and mortality. One study found that nearly $20 \%$ of Nebraska meat processing workers had been diagnosed with COVID-19 between March and July 2020 (Herstein et al., 2020).

In addition to health risks themselves, immigrants are also overrepresented in jobs that experienced the largest employment declines during the COVID-19 economic crisis. Employment for immigrant workers dropped by $19 \%$ (compared to $12 \%$ for US-born workers), with especially significant declines for Hispanic women and young adults (Kochhar, 2020). The loss of income and school closures has fueled food insecurity for immigrant families. Indeed, food insecurity in Latino households with children increased from $16.8 \%$ before the pandemic to $47 \%$ after (Schanzenbach \& Pitts, 2020). In nearly all states, undocumented immigrants have not been eligible for government support during the pandemic to mitigate these effects.

The disproportionate burden of COVID-19 borne by immigrants reflects longstanding structural inequalities in American access to health and economic opportunity. Compounding this unnecessary hardship, Latinos and Asian immigrants have experienced an uptick in discrimination and xenophobic attacks during the pandemic. President Trump and high-level officials deliberately referred to COVID-19 as "the Chinese virus", spreading misinformation and fueling racism against Asian Americans and immigrants (Wang, 2020). In March 2021, the FBI issued a warning of a potential surge in hate crimes against Asian Americans and civil rights organizations documented reports of racist attacks including verbal and physical assault. Latino immigrants' workers also face discrimination due to widespread fear that they have contracted the virus on the job. Latinos have been refused service, turned away from grocery stores in hard-hit communities, or fired for complaining about poor safety conditions (Gabbatt, 2020).

The public charge rule's racialized unwelcome mat has generated negative consequences substantially beyond those individuals directly affected by the rule's provisions. Subsequently, the pandemic exacerbated the unwelcome mat's negative consequences, pushing people away from public resources in a time when those resources are most needed. This doubly vulnerable context has persisted beyond the Trump administration, and even though the public charge rule was rescinded in March 2021, immigrant families continue to be particularly vulnerable to acute medical and economic hardship. Families may avoid medical care, including vaccine 
uptake (Mahoney, 2021; Chung, 2021) and public benefits for fear of being deemed a public charge; this parallels the fear that legal immigrants have of filing pandemic-related unemployment claims (Selyukh, 2020), and the distrust of state interactions that leads noncitizens to resist social isolation efforts intended to limit disease spread (Barry, 2020).

By spreading further than the programs and individuals specifically included, the fear and misinformation spurred by the public charge rule created an administrative burden that limited safety net access among a particularly vulnerable immigrant population during an acute economic and health crisis. The announcement and adoption of the policy has already caused substantial short- and long-term damage. Our findings begin to reveal the broad price of excessive administrative burden, especially when weaponized as dangerous and racist sludge.

\section{Notes}

1. For example, in an immigration case brought after the Trump administration revoked Temporary Protected Status, which could have repealed permanent residency for over 200,000 individuals in the U.S., the administration acknowledged its own racial animus: The ruling states in part: "Defendants do not deny that President Trump's alleged statements evidence racial animus (Ramos v Nielsen, p.31, 2018).”

2. The framework separates bureaucratic encounters into four categories: 1) encounters both initiated from and directed within an organization, 2) encounters initiated outside the organization, but directed to actors inside the organization, 3) transactions initiated inside an organization, but directed outside it, and 4) transactions initiated and directed outside the organization. The public charge expansion announcement therefore constituted a type 3 action (initiated inside, directed outside the bureaucracy), that affected how potential users of the safety net interacted with the state (a type 2 action). The announcement was amplified by media spreading fear and confusion (a type 4 action) and likely also affected lower-level government service providers to dissuade immigrants from safety-net participation (a type 1 action).

3. As noted previously, the most commonly cited source of information about the public charge rule was through media, social media, and an individual's social network (Bernstein et al. 2019).

\section{Acknowledgment}

We would like to thank the following individuals for helping us obtain state enrollment data: Ben Jaques-Leslie, Elisabet Eppes, Susan Sabatier, Paul Throne, Anh Tran, Patricia Mattinson, and two anonymous reviewers for their helpful comments. All errors are our own. 


\section{References}

Acevedo-Garcia, D., \& Stone, L. C. (2008). State variation in health insurance coverage for US citizen children of immigrants. Health Affairs, 27(2), 434446.

Alker, J., \& Pham, O. (2018). Nation's progress on children's health coverage reverses course. Washington: Georgetown University Center for Children and Families.

Andrasfay, T., \& Goldman, N. (2021). Reductions in 2020 US life expectancy due to COVID-19 and the disproportionate impact on the Black and Latino populations. Proceedings of the National Academy of Sciences, $118(5)$.

Artiga, S., Ndugga, N., \& Pham, O. (2021, January 13). Immigrant Access to COVID-19 Vaccines: Key Issues to Consider. In Kaiser Family Foundation. Retrieved from https://www.kff.org/racial-equityand-health-policy/issue-brief/immigrant-access-tocovid-19-vaccines-key-issues-to-consider/

Asad, A. L. (2020). Latinos' deportation fears by citizenship and legal status, 2007 to 2018. Proceedings of the National Academy of Sciences, 117(16), 8836-8844.

Barry, E. (2020, April 25). In a Crowded City, Leaders Struggle to Separate the Sick From the Well. In New York Times. Retrieved from https://www.nytimes.com/2020/04/25/us/coronavirus-chelseamassachusetts.html.

Bartlett, S., Burstein, N., \& Hamilton, W. (2004). Food stamp program access study. Washington, DC: Economic Research Service. http:/ /www.ers.usda. gov/publications/EFAN03013.

Bernstein, H., Gonzalez, D., Karpman, M., \& Zuckerman, S. (2019). One in seven adults in immigrant families reported avoiding public benefit programs in 2018. Washington, DC: Urban Institute.

Bernstein, H., McTarnaghan, S., \& Gonzalez, D. (2019). Safety Net Access in the Context of the Public Charge Rule. Washington, DC: Urban Institute.

Bonilla-Silva, E. (2001). White supremacy and racism in the post-civil rights era. Lynne Rienner Publishers.

Budiman, A. (2020). Key findings about US immigrants. Pew Research Centre. Retrieved from https://www.pewresearch.org/facttank/2020/08/20/key-findings-about-u-s- immigrants/.

Capps, R., Gelatt, J., \& Greenberg, M. (2020, March). The Public-Charge Rule: Broad Impacts, But Few Will Be Denied Green Cards Based on Actual Benefits Use.

In Migration Policy Institute. Retrieved from https://www.migrationpolicy.org/news/publiccharge-denial-green-cards-benefits-use.

Chen, Y. H., Glymour, M., Riley, A., Balmes, J., Duchowny, K., Harrison, R., ... \& Bibbins-Domingo, K. (2021). Excess mortality associated with the COVID-19 pandemic among Californians 18-65 years of age, by occupational sector and occupation: March through October 2020. medRxiv.

Chung, S. (2021). A Gap Exists in Vaccination Rates. New York City Lens. 4/22/2021. Retrieved from: https://nycitylens.com/gap-exists-vaccinationrates/.

Clark, E., Fredricks, K., Woc-Colburn, L., Bottazzi, M. E., \& Weatherhead, J. (2020). Disproportionate impact of the COVID-19 pandemic on immigrant communities in the United States. PLoS Neglected Tropical Diseases, 14(7), e0008484.

Cohen, M. S., \& Schpero, W. L. (2018). Household immigration status had differential impact on Medicaid enrollment in expansion and nonexpansion states. Health Affairs, 37(3), 394-402.

Currie, J. M. (2006). The take-up of social benefits. In Poverty, the Distribution of Income, and Public Policy, A. Auerbach, D. Card, \& J. Quigley (Eds.). New York, NY: Russell Sage.

Dan Keating et al., 'I Just Pray God Will Help Me': Racial, Ethnic Minorities Reel from Higher Covid-19 Death Rates, WASH. POST (Nov. 20, 2020), Retrieved from https://www.washingtonpost.com/graphics/2020/health/covid-racemortality-rate/.

Duncan, W. L., \& Horton, S. B. (2020). Serious challenges and potential solutions for immigrant health during COVID-19. Health Affairs Blog, 18.

Fix, M., \& Capps, R. (2017). Leaked Draft of Possible Trump Executive Order on Public Benefits Would Spell Chilling Effects for Legal Immigrants. Migration Policy Institute commentary, February.

Gabbatt, A. (2020). Latino workers face discrimination over spread of coronavirus in meat plants. The Guardian. Retrieved from https://www.theguardian.com/world/2020/may/25/latino-workerscoronavirus- discrimination-meat-plants

Gamboa, S. (2015). Donald Trump Announces Presidential Bid By Trashing Mexico, Mexicans. June 16, 2015. Retrieved from:

https://www.nbcnews.com/news/latino/donaldtrump-announces-presidential-bid- trashing-mexico-mexicans-n376521.

Gelatt, Julia. 2020 Revised. Immigrant Workers: Vital to the U.S. COVID-19 Response, Disproportionately Vulnerable. Washington, DC: Migration Policy Institute

Gonzalez, D., Karpman, M., Kenney, G. M., \& Zuckerman, S. (2020). Hispanic Adults in Families with Noncitizens Disproportionately Feel the Economic Fallout from COVID-19. Washington, DC: Urban Institute.

Gray, K., Trippe, C., Tadler, C., Perry, C., Johnson, P., \& Betson, D. (2019). National-and State-Level Estimates of WIC Eligibility and WIC Program Reach in 2017. 
Hacker, J. S., \& Pierson, P. (2020). Let them Eat Tweets: How the Right Rules in an Age of Extreme Inequality. Liveright Publishing.

Heinrich, C. J. (2016). The bite of administrative burden: A theoretical and empirical investigation. Journal of Public Administration Research and Theory, 26(3), 403420.

Herd, P., \& Moynihan, D. P. (2019). Administrative burden: Policymaking by other means. Russell Sage Foundation.

Herstein JJ, Degarege A, Stover D, Austin C, Schwedhelm MM, Lawler JV, et al. Characteristics of SARS-CoV-2 among meat processing workers in Nebraska, USA, and effectiveness of risk mitigation measures. Emerg Infect Dis. 2021 Apr, Accessed Feb 22, 2021. https://doi.org/10.3201/eid2704.204800

Hudson, J. L., \& Moriya, A. S. (2017). Medicaid expansion for adults had measurable 'welcome mat' effects on their children. Health Affairs, 36(9), 16431651.

Katznelson, I. (2005). When affirmative action was white: An untold bistory of racial inequality in twentieth-century America. WW Norton \& Company.

Kahn, R. L., Katz, D., \& Gutek, B. (1976). Bureaucratic encounters-An evaluation of government services. The Journal of Applied Behavioral Science, 12(2), 178198.

Kochhar, R. (2020). Hispanic women, immigrants, young adults, those with less education hit hardest by COVID-19 job losses. Pew Research Center. Retrieved from https://www.pewresearch.org/facttank/2020/06/09/hispanic-women-immigrantsyoung-adults-those-with-less-education-hit-hardestby-covid-19-job-losses/.

LoSasso, A. T. , \& Buchmueller, T. C. (2004). The effect of the state children's health insurance program on health insurance coverage. Journal of health economics, 23(5), 1059- 1082.

Mahoney, D. (2021). ICE entanglement reduces public safety. 4/23/21. Retrieved from: https://madison.com/wsj/opinion/column/sheriff-david-mahoney-ice-entanglement- reduces-public-safety/article_450701e4-1822-59c4-a832-d3a05027d3d1.html.

Mani, A., Mullainathan, S., Shafir, E., \& Zhao, J. (2013).

Poverty impedes cognitive function. Science, 341(6149), 976-980.

McInerney, M., Mellor, J. M., \& Sabik, L. M. (2021). Welcome Mats and On-Ramps for Older Adults: The Impact of the Affordable Care Act's Medicaid Expansions on Dual Enrollment in Medicare and Medicaid. Journal of Policy Analysis and Management, 40(1), 12- 41.

Migration Policy Institute 2020. United States Immigration Profile. Available from: https://www.migrationpolicy.org/data/state-profiles/state/demographics/US//. Accessed 12/2/2020.
Moynihan, D., Herd, P., \& Harvey, H. (2014). Administrative burden: Learning, psychological, and compliance costs in citizen-state interactions. Journal of Public Administration Research and Theory, 25(1), 43-69.

Mullainathan, S., \& Shafir, E. (2013). Scarcity: Why baving too little means so much. Macmillan.

National WIC Association (NWA). (2017, February 3). Draft Executive Order Potentially Impacting WIC. Retrieved from https://www.nwica.org/blog/clarification- draft-executive-order-potentially-impacting-wic\#.XuollRNKiF0.

National WIC Association (NWA). (2018, May 11). Update on WIC and Public Charge. Retrieved from https://www.nwica.org/blog/update-on-wic-andpublic- charge\#.XupFmhNKiF0.

Omi, M., \& Winant, H. (2014). Racial formation in the United States. Routledge.

Ramos v. Nielsen, 321 F. Supp. 3d 1083 (N.D. Cal. 2018). Retrieved on 3/10/2021 from https://casetext.com/case/ramos-v-nielsen-1.

Ray, V. (2019). A theory of racialized organizations. American Sociological Review, 84(1), 26- 53.

Rothstein, R. (2017). The color of law: A forgotten bistory of how our government segregated America. Liveright Publishing.

Sáenz, R., \& Manges Douglas, K. (2015). A call for the racialization of immigration studies: On the transition of ethnic immigrants to racialized immigrants. Sociology of Race and Ethnicity, 1(1), 166-180.

Schanzenbach, D. W., \& A. Pitts. (2020, July 9). Food Insecurity during COVID-19 in households with children: Results by racial and ethnic groups. Institute for Policy Research Rapid Research Report.

https://www.ipr.northwestern.edu/documents/reports/ipr-rapid-research-reports- pulse-hh-data-9july-2020-by-race-ethnicity.pdf

Selyukh, A. (2020, May 11). Will Filing For Unemployment Hurt My Green Card? Legal Immigrants Are Afraid. In NPR. Retrieved from: https://www.npr.org/2020/05/11/851463729/will -filing-for-unemployment-hurt-my- green-card-legal-immigrants-are-afraid.

Shear, M. D., \& Nixon, R. (2017). New Trump deportation rules allow far more expulsions. New York Times, 21. Retrieved from: https://www.nytimes.com/2017/02/21/us/politics/dhs-immigration-trump.html.

Sommers, B. D., \& Epstein, A. M. (2011). Why states are so miffed about Medicaid- economics, politics, and the "woodwork effect". New England Journal of Medicine.

Sonier, J., Boudreaux, M. H., \& Blewett, L. A. (2013). Medicaid 'welcome-mat' effect of Affordable Care Act implementation could be substantial. Health affairs, 32(7), 1319- 1325.

Sunstein, C. R. (2019). Sludge audits. Behavioural Public Policy, 1-20. 
Thaler, R. H. (2018). Nudge, not sludge.

Thaler, R. H., \& Sunstein, C. R. (2009). Nudge: Improving decisions about health, wealth, and happiness. Penguin.

U.S. Citizenship and Immigration Services (USCIS). (2019, December 4). Early American Immigration Policies. Retrieved from

https://www.uscis.gov/history-and- genealogy/our-history/overview-ins-history/early-american-immigration-policies.

Vargas, E. D., \& Pirog, M. A. (2016). Mixed-status families and WIC uptake: The effects of risk of deportation on program use. Social Science Quarterly, 97(3), 555-572.

Venkataramani, A. S., Bair, E. F., Dixon, E., Linn, K. A., Ferrell, W. J., Volpp, K. G., \& Underhill, K. (2020). Association Between State Policies Using Medicaid Exclusions to Sanction Noncompliance With Welfare Work Requirements and Medicaid Participation Among Low-Income Adults. J AMA Network Open, 3(5), e204579-e204579.
Vickery, K. P. (1974). 'Herrenvolk' democracy and egalitarianism in South Africa and the US South. Comparative Studies in Society and History, 16(3), 309-328.

Wang, C. (2020). Let's Stop the Scapegoating During a Global Pandemic. In American Civil Liberties Union. Retrieved from https://www.aclu.org/news/racialjustice/lets- stop-the-scapegoating-during-a-globalpandemic/

Waters, M. C., \& Kasinitz, P. (2015). The war on crime and the war on immigrants: racial and legal exclusion in the twenty-first-century United States. Fear, Anxiety, and National Identity: Immigration and Belonging in North America and Western Europe. New York: Russell Sage Foundation, 115-144.

Watson, T. (2014). Inside the refrigerator: Immigration enforcement and chilling effects in Medicaid participation. American Economic Journal: Economic Policy, 6(3), 313-38.

Williamson, V., Skocpol, T., \& Coggin, J. (2011). The Tea Party and the remaking of Republican conservatism. Perspectives on Politics, 25-43. 